\title{
Artificial selection and heritability of sperm length in Gryllus bimaculatus
}

\author{
EDWARD H. MORROW* \& MATTHEW J. G. GAGE† \\ Population and Evolutionary Biology Research Group, Nicholson Building, School of Biological Sciences, \\ University of Liverpool, Liverpool, L69 3BX, U.K.
}

\begin{abstract}
The adaptive significance of variation in sperm size remains poorly understood but there has been even less attention focused on the genetic mechanisms controlling spermatozoal traits (only three species have been studied). Here we explore heritability and artificial selection of sperm length in the cricket Gryllus bimaculatus. Using a within-family selection design we selected sperm with increasing and decreasing sperm size and bred divergence across five generations. Although we recorded no significant parent-offspring heritability, realized heritability from a within-family analysis was significant at $0.52 \pm 0.06 \mathrm{SE}(P=0.01)$ and we successfully achieved significant divergence. However, we only achieved a response when the maternal line was incorporated into selection (from the $\mathrm{F}_{1}$ onwards) and our findings therefore suggest that sperm length in G. bimaculatus is a sex-linked trait that is influenced by genes which are active on the female chromosome. Accordingly, sperm length heritability in G. bimaculatus can only be measured using a within-family design because the spermatozoal phenotype is sex-limited (to males) while the genotype is sex-linked (to females). The evolutionary significance of the heritability of sperm length is discussed with reference to sex-linkage of this important sex-limited trait.
\end{abstract}

Keywords: artificial selection, Gryllus bimaculatus, heritability, sperm competition, sperm length.

\section{Introduction}

Spermatozoal size and structure show great variation across species (Stockley et al., 1997; Birkhead \& Møller, 1998; Gage et al., 1998; Morrow \& Gage, 2000) from the tiny aflagellate amoeboid gametes of nematodes (LaMunyon \& Ward, 1998) to the giant sperm of Drosophilids (Pitnick et al., 1995). Reasons for this variation in sperm structure remain poorly understood, but recently studies have attempted to explain why there is variation in sperm size. In internal fertilisers, sperm have evolved to function within the environment of the female reproductive tract and sperm size is associated with female reproductive tract dimensions across ptilid beetles (Dybas \& Dybas, 1981), birds (Briskie \& Montgomerie, 1992), Drosophilids (Pitnick et al., 1995, 1999), diopsid flies (Presgraves et al., 1999) and moths (Morrow \& Gage, 2000). Sperm competition (when sperm from different males mix and compete for a female's ova, Parker, 1970) is one force that is positively

*Correspondence and present address: Department of Ecology and Environmental Science, University of Umeå, SE 901-87 Umeå, Sweden. E-mail: Ted.Morrow@eg.umu.se

$\dagger$ Present address: School of Biological Sciences, University of East Anglia, Norwich, NR4 7TJ, U.K. (birds: Briskie \& Montgomerie, 1992; butterflies: Gage, 1994; primates and rodents: Gomendio \& Roldan, 1991) and negatively (fishes: Stockley et al., 1997) associated with sperm size across taxa. There is also evidence from single-species studies that increased sperm size improves a male's fertilization success in mites (Radwan, 1996), nematodes (LaMunyon \& Ward, 1998) and dung flies (Otronen et al., 1997).

In addition to between-species differences, there is significant variation in sperm size between individual males within a species. Between-male variation in sperm head size was first identified in bulls (Williams \& Savage, 1925) and humans (Moench \& Holt, 1932). Subsequently, significant intraspecific variation in total sperm length has been found for several species of rodents (Friend, 1936; Braden, 1959; Illisson, 1969), insects (Otronen et al., 1997; Ward, 1998), and other taxa (Ward, 1998). Ward (1998) predicted that this intraspecific variation in sperm morphometry could be widespread and Morrow \& Gage (2001) screened 10 species from a wide range of invertebrate and vertebrate taxa using identical techniques and found that significant between-male variation in sperm size was recorded for every species measured. The study included examinations of populations that were likely to have low 
heterozygosity, such as laboratory or island populations. In addition to total sperm length, there was also universal and significant between-male variance in the sizes of the head, midpiece and flagellum in every species in which these components were visible (Morrow \& Gage, 2001). The evolutionary reasons for persistent differences between males in sperm morphometry are still unclear, as are the consequences to the fertility or fertilization success of individual males. Sperm size is unlikely to be a neutral trait given the well documented interspecific evidence (see Birkhead \& Møller, 1998) and given that sperm represent a significant stage in male reproduction, and therefore are the focus of intense selection.

Despite attempting to explain the adaptive significance of variation in sperm size, there is limited understanding of the genetic mechanisms controlling variation in sperm size. Sperm size is not likely to be a condition-dependent trait since all males within a population are selected for competition and fertilization within a common reproductive environment. The few studies which have explored condition-dependence in sperm size concur with this interpretation (Vawda \& Mandlwana, 1990; Blay \& Yuval, 1997; Birkhead et al., 1999), for example, male moths raised on a severely limiting diet partitioned resources away from sperm number production but maintained sperm size (Gage \& Cook, 1994). Estimates of heritability $\left(h^{2}\right)$ are available for several sperm traits from rabbits (Oryctolagus cuniculus sperm head length $0.72 \pm 0.18$; width $0.71 \pm 0.13$; area $0.74 \pm 0.15$; and shape $0.56 \pm 0.13$ (Napier, 1961)), mice (Mus musculus midpiece length $0.97 \pm 0.36$ (Woolley \& Beatty, 1967) and $0.76 \pm 0.02$ (Woolley, 1971); and head shape $\approx 0.9$ (Illisson, 1969)) and dung flies (Scathophaga stercoraria sperm length $\approx 0.67$ (Ward, 2000)). All of these estimates are high relative to those found for other fitness traits (mean $h^{2} \pm$ SE life history $0.26 \pm 0.01$; physiology $0.33 \pm$ 0.03 ; behaviour $0.30 \pm 0.02$; morphology $0.46 \pm 0.004$ (Mousseau \& Roff, 1987)).

In this study we use the natural variation in sperm size between males as the basis for artificial selection upon sperm length in order to establish the degree of response to selection. Selection experiments on the midpiece length of mouse sperm showed strong responses to selection and high estimates of heritability, from $0.76 \pm 0.02$ to $0.97 \pm 0.36$ (Woolley \& Beatty, 1967; Woolley, 1971) but only 13 generations were followed. Here we use the field cricket Gryllus bimaculatus as our genetic model. Not only does sperm size vary significantly between males of the same population, but we know that sperm length is male-specific and is consistent for individual males producing spermatophores on different days (Morrow \& Gage, 2001).
In addition to examining responses to selection, we explore whether sperm length genes are active in the male or female genome. Ward (2000) has shown sperm length to be heritable in the dung fly and that genes coding for sperm length may well be X-linked; thus selection on males and females may be important to the evolution of sperm length. Gryllus bimaculatus, in common with the majority of the Orthoptera, has an $\mathrm{XO} / \mathrm{XX}$ system of sex determination (Hewitt, 1979). Thus sex-linkage of sperm size in this species, if it occurred, would be restricted to the X chromosome. We therefore explore the heritability of sperm length in G. bimaculatus using a within-family artificial selection design (Falconer \& Mackay, 1996) that allows us both to measure the degree of genetic response, and to quantify any sex-linkage.

\section{Materials and methods}

\section{Study animal and rearing conditions}

The cricket Gryllus bimaculatus (Gryllidae) is a hemimetabolous exopterygote that can be reared under laboratory conditions. In order to minimize any possible environmental effects on sperm size, all crickets at every stage of their life cycle and for each generation were reared under identical conditions. Individuals were reared at $28 \pm 2{ }^{\circ} \mathrm{C}$ under a 14:10 L:D light regime. Adults and nymphs were provided with food ad libitum in the form of rodent pellets (CRM (P), Special Diet Services, U.K.) and water (in vials plugged with cotton wool). Mating pairs were provided with an oviposition dish (replaced on alternate days) comprising a $50-\mathrm{mm}$ diameter Petri dish base filled with a wad of damp cotton wool, into which females will readily oviposit. Removed dishes were kept damp and covered with a lightly fitting lid and incubated at $28 \pm 2{ }^{\circ} \mathrm{C}$ under a 14:10 L:D cycle until larval crickets began to emerge approximately 10 days later.

\section{Spermatophore collection and sperm measurement}

Males were selected according to the mean length of sperm sampled from a spermatophore collected at least 10 days after adult eclosion, when sexually mature (Simmons, 1986).

Male G. bimaculatus produce a single spermatophore at a time, and it hardens within 1-2 $\mathrm{h}$ after which it may be gently removed from within the valves surrounding the genital opening using a pair of soft forceps. Spermatophores removed in this way were submerged in $20 \mathrm{~mL}$ of distilled water and cracked open using a pair of modified pincer-like forceps. The sperm were 
gently dispersed by agitating the sperm mass and spermatophore fragments with a pair of straight forceps for approximately $30 \mathrm{~s}$. This resulted in an even dispersion of the entire ejaculate without sperm clumping and with a negligible frequency of fragmented sperm. Severe sperm clumping occurs if spermatophores are allowed to evacuate normally into water.

A direct method was used to measure sperm total length. Magnified phase-contrast images of sperm were relayed by video to a flat-screen monitor and the image then drawn onto an acetate sheet. These tracings were photocopied onto paper and measurements of their length taken using a Silva online-5 digital map-measurer (Field \& Trek Ltd, U.K.). This method of measuring sperm length is highly repeatable both between measuring events (repeated measures GLM, $F=155033$, $P<0.001$ ) and between observers (repeated measures GLM, $F=184710, P<0.001)$ and has been used successfully in other studies (e.g. Morrow \& Gage, 2000; Morrow \& Gage, 2001). Mean sperm length was determined for each male from measures of 10 intact sperm and this level of sampling results in a representative mean (Morrow \& Gage, 2000). Mean sperm length in G. bimaculatus measured in this way has been found to range from less than $900 \mu \mathrm{m}$ to over $1000 \mu \mathrm{m}$ (Morrow \& Gage, 2001).

\section{Artificial selection protocol}

Initially 39 virgin male crickets were removed randomly from the stock population to be included in the founding population. Each individual was isolated prior to pairing in a small cage $(0.5 \mathrm{~L})$ and provided with ad libitum food and water. All 39 males were screened for sperm length, and the 10 longest and 10 shortest males were used to establish 'long' and 'short' familial lines. In this first P generation, 'long' or 'short' males were paired with random stock virgin females.

The 20 separate families of larval crickets were reared to maturity under the same environmental conditions as the stock, but in 5-L cages. In this $\mathrm{F}_{1}$ generation, five males from each of the 'long' and 'short' families were screened for sperm length $(n=100$ males in total). Within each family, the male with either the longest or shortest sperm was then chosen to be the sire of the next generation. Accordingly, 10 'long' and 10 'short' families were continued and this regime was repeated and carried forward to the $\mathrm{F}_{4}$ generation.

In the $F_{1}$ and subsequent generations, the female 'long' or 'short' genotype was incorporated into the selection protocol. Virgin females were randomly isolated from each family and paired with males from the same selection criteria (i.e. either 'long' or 'short') but not from the same family within the sperm length line.
In subsequent generations the families from which the females were taken were rotated around the 10 families of the 'long' or 'short' lines to minimize inbreeding.

\section{Initial estimate of heritability}

To measure the response to selection an initial estimate of heritability must be determined. It must be noted that if there is sex-linkage of a trait then this value can be an under-estimate because the offspring phenotype may not be under the control of the paternal genotype. Offspringparent regressions were determined over two generations before selection had begun. Because sperm lengths were measured for offspring from either end of the parental distribution (leading to bimodality), our initial estimate of heritability was based on a regression using a bimodal distribution. The offspring means were weighted because of unequal sample sizes within families (mean $n$ of offspring $=4.85$, range $=4-5$; Kempthorne \& Tandon, 1953; page 179, Falconer \& Mackay, 1996). The weighting factor $w_{n}$ is applied to the mean values of $n$ offspring from each family. The estimate of heritability $\left(h^{2}\right)$ is simply double the coefficient of the slope $\left(b_{\mathrm{Op}}\right)$, because only one parent's phenotype is measured. Thus $h^{2}=2 b_{\mathrm{Op}}$.

\section{Heritability and response using within-family selection}

A strict within-family design was employed as the method of selection. This enables both calculation of the degree of response, and also shows whether sex-linkage occurs. The realized heritability $\left(h_{w}^{2}\right)$ is therefore calculated from a modified version of that calculated for an individual selection design $\left(h^{2}\right)$ (p. 236, Falconer \& Mackay, 1996):

$h_{w}^{2}=h \frac{(1 \quad r)}{(1 \quad t)}$

In addition the calculation for the expected response may also be modified to include the additional information provided by knowledge of individuals measured in the context of their respective families (p. 236, Falconer \& Mackay, 1996).

\section{Realized heritability}

The response to selection also provides an estimate of the realized heritability from the regression of response over the cumulative selection differential. As there were no control line measurements available, the response was calculated as generation means for each line subtracted from one another. The cumulative selection differential must also be appropriately weighted accord- 
ingly because the number of offspring measured within each family was not maintained at exactly five. The selection differentials from each line are added to one another for each round of selection (Falconer \& Mackay, 1996).

\section{Results}

\section{Initial estimate of heritability}

Because of unequal numbers of full-sib offspring measured per family we applied a weighting correction to the heritability estimate (p. 179 Falconer \& Mackay, 1996). Sperm length heritability was $0.29 \quad( \pm 0.20)$ which was not significant $(y=0.15 x+841, F=2.24$, $\left.r^{2}=0.11, P=0.15, n=20\right)$ but it produces an initial estimate that can be used for the primary aim of measuring responses to selection (Falconer \& Mackay, 1996). It should be noted that this nonsignificant result could be explained if there was a sex-linked effect from the female genotype which, for sperm, obviously cannot be phenotypically described in a simple parent-offspring relationship.

\section{Response to selection}

Estimates for the average responses per generation from $F_{1}$ to $F_{4}$ are presented in Fig. 1 and by generation in Table 1. Responses were $r^{2}=0.95, P=0.03$ and $r^{2}=0.66, P=0.18$ for the 'short' and 'long' lines, respectively (short $y=-6.56 x+982.9$; long $y=5.59 x+$ 983.5; Fig. 1).

The mean divergence per generation is presented in Fig. $2(y=12.15 x+0.63)$ and by generation in

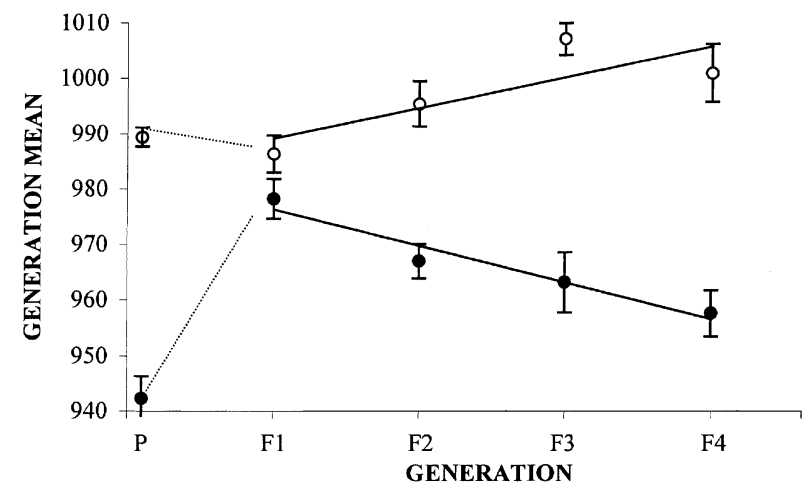

Fig. 1 Response of the short line (closed symbol) and the long line (open symbol) over four generations of selection for sperm length in Gryllus bimaculatus (generation means are given in $\mu \mathrm{m}$ ). Note that offspring traits from the $\mathrm{P}$ generation return to the population mean and a response is only achieved from $F_{1}$ onwards when the maternal genotype is incorporated into selection.

(C) The Genetics Society of Great Britain, Heredity, 87, 356-362.
Table 1 Expected responses (in $\mu \mathrm{m}$ ) calculated for comparison with the actual response observed to selection for sperm length in Gryllus bimaculatus

\begin{tabular}{lcc}
\hline Line & $\begin{array}{c}\text { Expected response } \\
\text { when } h^{2}=0.29\end{array}$ & $\begin{array}{c}\text { Observed response } \\
\text { from } \mathrm{F}_{1} \text { to } \mathrm{F}_{2}\end{array}$ \\
\hline Short & 4.52 & 11.28 \\
Long & 4.24 & 9.09 \\
\hline
\end{tabular}

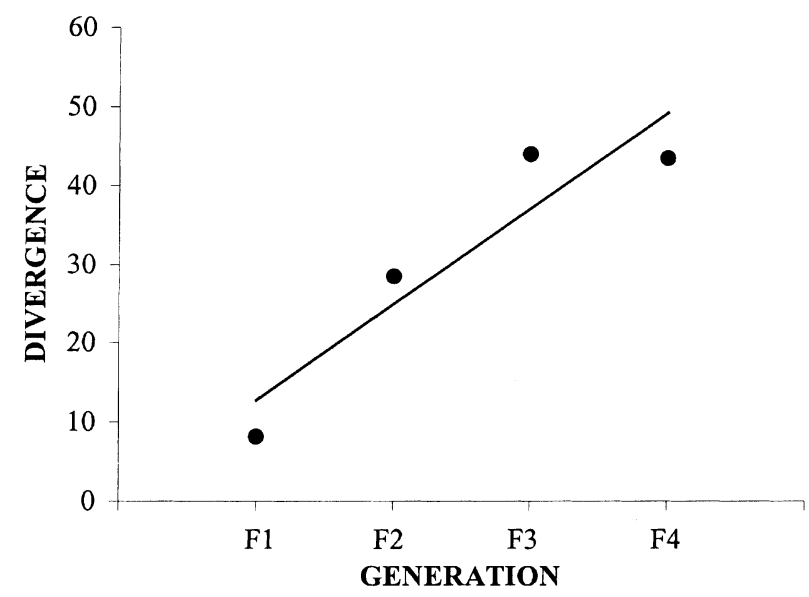

Fig. 2 Divergence between short and long lines over four generations $\left(\mathrm{F}_{1}-\mathrm{F}_{4}\right)$ of selection for sperm length in Gryllus bimaculatus (generation means are given in $\mathrm{m}$ ).

Table 2 Estimates of average response (in $\mu \mathrm{m}$ ) per generation $(R)$ to selection for sperm length in Gryllus bimaculatus

\begin{tabular}{lr}
\hline & Mean response \\
\hline Short & $6.56 \pm 1.12$ \\
Long & $5.59 \pm 2.81$ \\
Divergence & $12.15 \pm 3.40$ \\
\hline
\end{tabular}

Table 2. Although $86 \%$ of the variation was explained by the regression line $\left(r^{2}=0.86, P=0.07\right)$, only four rounds of selection generates no statistical significance, despite an apparent response.

\section{Heritability and response using within-family selection}

The within-family estimate of heritability $\left(h_{w}^{2}\right)$ was 0.1956 . The within-family response $R_{w}$ calculated for the short line was 2.34, and for the long line was 2.19.

The expected response of within-family selection may be compared with the expected response of individual selection by dividing one by the other, thus: 


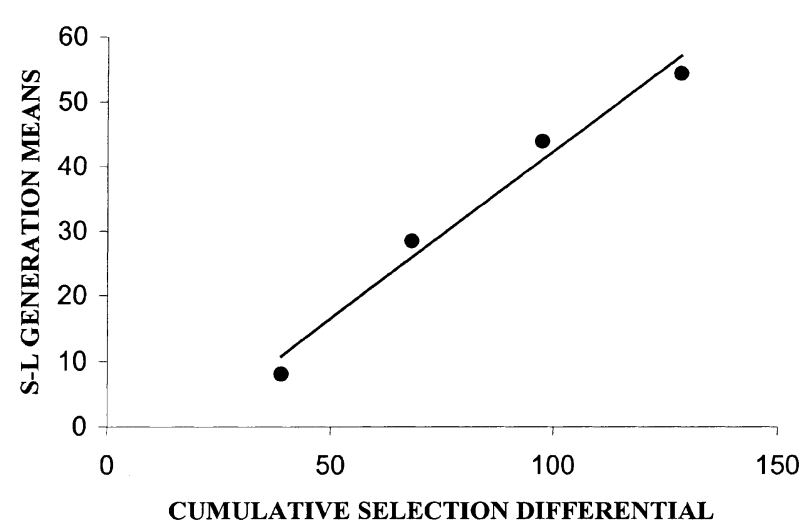

Fig. 3 Response vs. selection for the two selection lines of Gryllus bimaculatus combined, providing an estimate of realized heritability $\left(h^{2} \pm \mathrm{SE}\right)$ from the slope of the regression of $0.52 \pm 0.06$.

\section{$R_{w} / R=\left(\begin{array}{ll}1 & r\end{array}\right) \sqrt{ }\left\{\left(\begin{array}{ll}n & 1\end{array}\right) /[n(1 \quad t)]\right\}=0.52$}

where $n=5$ offspring and $t$ is the intraclass correlation coefficient, estimated from the offspring-parent regression. In other words the efficiency of the within-family selection relative to an alternative individual selection protocol is approximately one half.

\section{Estimate of realized heritability}

The primary aim of this study was to estimate realized heritability in order to measure the degree of response to selection. Realized heritability, calculated from the slope of a line fitted to the combined generation means vs. the cumulative selection differentials, was $0.52 \pm 0.06$ $\left(r^{2}=0.98, F=79.33, n=4, P=0.01\right.$; Fig. 3$)$. The slopes for the upward (long) and downward (short) selected lines were $0.30 \pm 0.02 \quad\left(r^{2}=0.97, \quad F=72.02, \quad n=4\right.$, $P=0.01)$ and $0.41 \pm 0.05\left(r^{2}=0.98, F=17.45, n=4\right.$, $P=0.053)$, respectively.

\section{Discussion}

Our selection experiment shows that sperm length in Gryllus bimaculatus does have a considerable genetic component; elongation and reduction of sperm length was successfully achieved using a within-family design of artificial selection (Falconer \& Mackay, 1996) and realized heritability was significant with $h^{2}=0.52$. Selection was attained over a relatively short period involving four rounds of within-family selection proper.

Our experiment was not designed to provide a reliable estimate of heritability from an individual parentoffspring regression, because we also anticipated that sperm length could be under genetic control from the maternal genotype. Heritability of single-sex traits such as gamete phenotype cannot be fully measured using offspring-parent regression because the phenotype is only expressed in a single parent. Furthermore, if the expressed trait is genotypically coded by the nonexpressing parent, it is impossible to measure parentoffspring heritability. This phenomenon may explain why we calculated a nonsignificant estimate of $h^{2}$ for sperm length from the offspring-parent regression (0.29), but a significant realized heritability from the withinfamily estimate (0.52) when maternal genotypes were incorporated into the selection protocol from $F_{1}$ to $F_{4}$ (Figs 1-3), although genetic drift cannot be ruled out.

Heritability estimates of sperm dimensions have been measured for only three other species: rabbits, mice and yellow dung flies (see Introduction). Dung flies (Scathophaga stercoraria) have significantly heritable sperm length at 0.67 (Ward, 2000), however, Ward also showed that sperm length within the dung fly may be sex-linked to the $\mathrm{X}$-chromosome because there was a significant relationship between a male's sperm length and his maternal grandfather (Ward, 2000). In our study of G. bimaculatus we find similar evidence that sperm length may be influenced by female-specific genes. The sex determination system within $G$. bimaculatus is $\mathrm{XO} /$ XX (Hewitt, 1979) and males therefore only have one set of sex chromosomes, in contrast to dung flies that have an additional Y-chromosome. We have yet to determine the nature of sex-linkage for sperm-length genes and whether linkage is partial or complete. Sex-linkage of genes may only be estimated using information on trait size from reciprocal hybrid experiments, where the trait values of these hybrids are compared to the difference between the parental lines used to create them (Reinhold, 1998).

Traditionally, traits that are closely related to fitness are expected to have lower heritabilities because of stabilizing selection (Fisher, 1930; Falconer \& Mackay, 1996). This is supported by an analysis of a large number of traits by Mousseau \& Roff (1987) who found that life history traits generally had lower heritabilities than morphological traits. We do not yet know the degree to which sperm length is subject to stabilizing or directional selection, or both. Sperm competition could select directionally and there is evidence that sperm competition level and success are associated with bigger sperm (LaMunyon \& Ward, 1998, 1999). However the female reproductive tract is an environment likely to generate stabilizing selection and there is evidence for associations between storage site dimensions and sperm size across taxa (e.g. Briskie \& Montgomerie, 1992; Pitnick et al., 1999; Presgraves et al., 1999; Morrow \& Gage, 2000). Whatever the forces selecting for sperm length optima, it is counterintuitive that a male fitness 
trait is controlled by genes that are active on maternal chromosomes. If this is the mechanism for sperm phenotype control, then it does explain why we record significant variation between individual males within a population in sperm size. In a survey of 10 vertebrate and invertebrate taxa, Morrow \& Gage (2001) found significant variation in sperm head, midpiece, flagellum and total dimensions between males within a population. If sperm size is maintained through indirect selection (since the females carrying the genes cannot themselves be selected) then between-male variation in sperm size could be maintained. It remains unclear, however, why a seemingly important fitness trait such as the male gamete is controlled by genes that cannot be selected directly.

\section{Acknowledgements}

This work was funded by a NERC research studentship to EHM, and a Royal Society Fellowship to MJGG. We are grateful for discussions with Geoff Parker, Scott Pitnick, Tom Tregenza and Ian Hastings.

\section{References}

BIRKHEAD, T. R. AND Møller, A. P. 1998. Sperm Competition and Sexual Selection, 1st edn. Academic Press, London.

BIRKHEAD, T. R., FLETCHER, F. AND PELLATT, E. J. 1999. Nestling diet, secondary sexual traits and fitness in the zebra finch. Proc. R. Soc. B, 266, 385-390.

BLAY, S. AND YUVAL, B. 1997. Nutritional correlates of reproductive success of male Mediterranean fruit flies (Diptera: Tephritidae). Anim. Behav., 54, 59-66.

BRADEN, A. W. H. 1959. Strain differences in the morphology of the gametes of the mouse. Aust. J. Biol. Sci., 12, 65-71.

BRISKIE, J. V. AND MONTGOMERIE, R. 1992. Sperm size and sperm competition in birds. Proc. R. Soc. B, 247, 89-95.

DYBAS, L. K. AND DYBAS, H. S. 1981. Coadaptation and taxonomic differentiation of sperm and spermathecae in featherwing beetles. Evolution, 35, 168-174.

FALCONER, D. S. AND MACKAY, T. F. C. 1996. Introduction to Quantitative Genetics, 4th edn. Longman, London.

FISHER, R. A. 1930. The Genetical Theory of Natural Selection, 1 st edn. Clarendon Press, Oxford.

FRIEND, G. F. 1936. The sperms of the British Muridae. Q. J. Microscop. Sci., 78, 419-443.

GAGE, M. J. G. 1994. Associations between body size, mating pattern, testis size and sperm lengths across butterflies. Proc. R. Soc. B, 258, 247-254.

GAGE, M. J. G. AND COOK, P. A. 1994. Sperm size or numbers? Effects of nutritional stress upon eupyrene and apyrene sperm production strategies in the moth Plodia interpunctella (Lepidoptera: Pyralidae). Funct. Ecol., 8, 594-599.

GAGE, M. J. G., STOCKLEY, P. AND PARKeR, G. A. 1998. Sperm morphometry in the Atlantic salmon. J. Fish Biol., 53, 835-840.
GOMENDIO, M. AND ROLDAN, E. R. S. 1991. Sperm competition influences sperm size in mammals. Proc. R. Soc. B, 243, 181-185.

HEWITT, G. M. 1979. Insecta 1. Orthoptera: Grasshoppers and Crickets, 1st edn. Gebrüder Borntraeger, Berlin.

ILLISSON, L. 1969. Spermatozoal head shape in two inbred strains of mice and their $\mathrm{F}_{1}$ and $\mathrm{F}_{2}$ progenies. Aust. J. Biol. Sci., 22, 947-963.

KEMPTHORNE, O. AND TANDON, O. B. 1953. The estimation of heritability by regression of offspring on parent. Biometrics, 9, 90-100.

LAMUNYON, C. AND WARD, s. 1998. Larger sperm outcompete smaller sperm in the nematode Caenorhabditis elegans. Proc. R. Soc. B, 265, 1997-2002.

LAMUNYON, C. W. AND WARD, S. 1999. Evolution of sperm size in nematodes: sperm competition favours larger sperm. Proc. R. Soc. B, 266, 263-267.

MOENCH, G. L. AND HOLT, H. 1932. Biometrical studies of head lengths of human spermatozoa. J. Lab. Clin. Med., 17, 297-316.

MORRow, E. H. AND GAGE, M. J. G. 2000. The evolution of sperm length in moths. Proc. R. Soc. B, 267, 307-313.

MORROW, E. H. AND GAGE, M. J. G. 2001. Consistent significant variation between individual males in spermatozoal morphometry. J. Zool. Lond., 254, 147-153.

MOUSSEAU, T. A. AND ROFF, D. A. 1987. Natural selection and the heritability of fitness components. Heredity, 59, 181-197.

NAPIER, R. A. N. 1961. Fertility in the male rabbit III. Estimation of spermatozoan quality by mixed insemination, and inheritance of spermatozoan characters. J. Reprod. Fertility, 2, 273-289.

OTRONEN, M., REGUERA, P. AND WARD, P. I. 1997. Sperm storage in the yellow dung fly Scathophaga stercoraria: identifying the sperm of competing males in separate female spermathecae. Ethology, 103, 844-854.

PARKER, G. A. 1970. Sperm competition and its evolutionary consequences in the insects. Biol. Rev., 45, 525-567.

PITNICK, S., MARKOW, T. A. AND SPICER, G. S. 1995. Delayed male maturity is a cost of producing large sperm in Drosophila. Proc. Natl. Acad. Sci. U.S.A., 92, 10614-10618.

PITNICK, S., MARKOW, T. A. AND SPICER, G. S. 1999. Evolution of multiple kinds of female sperm-storage organs in Drosophila. Evolution, 53, 1804-1822.

PRESGRAVES, D. C., BAKER, R. H. AND WILKINSON, G. S. 1999. Coevolution of sperm and female reproductive tract morphology in stalk-eyed flies. Proc. R. Soc. B, 266, 1041-1047.

RADWAN, J. 1996. Intraspecific variation in sperm competition success in the bulb mite: a role for sperm size. Proc. R. Soc. $B, 263,855-859$.

REINHOLD, K. 1998. Sex linkage among genes controlling sexually selected traits. Behav. Ecol. Sociobiol., 44, 1-7.

SIMMONS, L. W. 1986. Inter-male competition and mating success in the field cricket, Gryllus bimaculatus (De Geer). Anim. Behav., 34, 567-579.

STOCKLEY, P., GAGE, M. J. G., PARKER, G. A. AND MøLler, A. P. 1997. Sperm competition in fishes: the evolution of testes size and ejaculate characteristics. Am. Nat., 149, 933-954. 
VAWDA, A. I. AND MANDLWANA, J. G. 1990. The effects of dietary protein deficiency on rat testicular function. Andrologia, 22, 575-583.

WARD, P. I. 1998. Intraspecific variation in sperm size characters. Heredity, 80, 655-659.

WARD, P. I. 2000. Sperm length is heritable and sex-linked in the yellow dung fly Scathophaga stercoraria. J. Zool. Lond., 251, 349-353.
WILliams, W. W. AND SAVAGE, A. 1925. Observations of the seminal micropathology of bulls. Cornell Veterinarian, 15, 353-374.

WOOLLEY, D. M. 1971. Selection for the length of the spermatozoan midpiece in the mouse. Genet. Res., 16, 261-275.

WOOLLEY, D. M. AND BEATTY, R. A. 1967. Inheritance of midpiece length in mouse spermatozoa. Nature, 215, 94-95. 